\title{
Antibiotic resistance among ocular pathogens: current trends from the ARMOR surveillance study (2009-2016)
}

This article was published in the following Dove Medical Press journal: Clinical Optometry

\author{
Randall K Thomas' \\ Ron Melton' \\ Penny A Asbell ${ }^{2}$ \\ 'Educators in Primary Eye Care, LLC, \\ Concord, NC, USA; ${ }^{2}$ Department \\ of Ophthalmology, Hamilton Eye \\ Institute, University of Tennessee \\ Health Science Center, Memphis, TN \\ USA
}

\begin{abstract}
Background: The Antibiotic Resistance Monitoring in Ocular micRoorganisms study is an ongoing surveillance study that tracks antibiotic resistance among bacterial isolates from ocular infections across the United States. We report antibiotic resistance rates and trends from 2009 through 2016.
\end{abstract}

Materials and methods: Staphylococcus aureus, coagulase-negative staphylococci (CoNS), Streptococcus pneumoniae, Pseudomonas aeruginosa, and Haemophilus influenzae from various ocular infections were obtained from participating United States centers. Isolates were sent to a central laboratory for determination of antibiotic resistance profiles. Minimum inhibitory concentrations were determined by broth microdilution according to the Clinical and Laboratory Standards Institute for drugs from more than ten antibiotic classes, and isolates were classified as susceptible or resistant based on systemic breakpoints, wherever available. Resistance rates were also evaluated based on decade of patient life and longitudinally over the 8-year time period. Results: A total of 1,695 S. aureus, 1,475 CoNS, 474 S. pneumoniae, 586 H. influenzae, and $599 P$. aeruginosa were collected from 87 sites. Resistance was high among staphylococci and pneumococci, with methicillin resistance detected in 621 (36.6\%) S. aureus and 717 (48.6\%) CoNS isolates. Multidrug resistance ( $\geq 3$ drug classes) was observed among staphylococci, particularly in methicillin-resistant (MR) isolates (MR S. aureus [MRSA]: 76.2\%; MR CoNS [MRCoNS]: 73.5\%). Differences in methicillin resistance among staphylococci were observed based on patient age, with higher rates observed in older patients $(P<0.0001)$. For certain organism-antibiotic combinations, there were significant changes in resistance over time, including a decrease in methicillin resistance among $S$. aureus (but not CoNS); no notable trends were observed for S. pneumoniae.

Conclusion: Antibiotic resistance was prevalent among gram-positive organisms, and MR staphylococcal isolates were more likely to be multidrug resistant. Although a small decrease in methicillin resistance was observed among $S$. aureus over time, the continued high prevalence of in vitro methicillin resistance should be considered when treating patients with ocular infections. Keywords: ophthalmic infections, bacterial pathogens, topical antimicrobials, multidrug resistance, methicillin resistance

\section{Introduction}

Bacterial resistance to antibiotics, acquired primarily through genetic mutations, is high globally, with several contributing factors identified. ${ }^{1}$ Studies have shown that practices such as overprescription of antibiotics, use of inappropriate dosing regimens, and widespread agricultural use of antibiotics have contributed significantly to the problem of antibiotic resistance, with resistant bacteria posing considerable risk to
Correspondence: Randall K Thomas Educators in Primary Eye Care, LLC. 6017 Havencrest $\mathrm{Ct}$, NW, Concord, NC 28027, USA

Tel +l 704792602

Email Irandallthomas@gmail.com 
the resolution of systemic infections. ${ }^{2}$ Antibiotic resistance has also been observed among pathogens causing ocular infections specifically, with factors such as empirical prescribing of antibiotics, short-term exposure to antibiotics, and repeated exposure to the same antibiotic identified as contributing to resistance of ocular pathogens, as well as leading to changes in resident ocular flora. ${ }^{3-7}$ Antimicrobial prophylaxis, used for the prevention of endophthalmitis and postoperative infection in patients undergoing ocular surgery, ${ }^{8,9}$ could also contribute to increased resistance rates among ocular pathogens.

Staphylococcus aureus and coagulase-negative staphylococci (CoNS; most frequently Staphylococcus epidermidis), which colonize the surfaces of the eyes and eyelids, are important contributors to ocular infections. ${ }^{10,11}$ While $S$. aureus accounts for a large proportion of bacterial keratitis cases $(>25 \%),{ }^{11,12}$ CoNS accounts for the majority $(>30 \%)$ of endophthalmitis cases, ${ }^{11,13-15}$ especially acute episodes that develop after cataract surgery, ${ }^{16,17}$ and both are increasingly recognized as common causes of conjunctivitis when present above established quantitative levels. ${ }^{18,19}$ Similarly, both Streptococcus pneumoniae and Haemophilus influenzae are commonly isolated from patients with bacterial conjunctivitis, especially children, ${ }^{10,20}$ and the significant ocular pathogen Pseudomonas aeruginosa is a leading cause of bacterial keratitis in contact lens wearers. ${ }^{21}$

Ocular infections caused by these common bacterial pathogens are treated with a wide variety of antibiotics. Infection with resistant organisms can complicate antibiotic selection, increasing the risk of treatment failure with potentially sightthreatening consequences. ${ }^{6}$ Since many antibiotics are also prescribed systemically to treat a broad spectrum of other bacterial infections, cross-resistance can complicate treatment further. ${ }^{22}$ Currently, besifloxacin, a chlorofluoroquinolone indicated for the treatment of bacterial conjunctivitis, is the only antibiotic exclusively formulated for topical ophthalmic use. ${ }^{23}$ Since its administration is solely topical, resistance to besifloxacin has the potential to be lower than that observed for other fluoroquinolones, which are also administered systemically. ${ }^{24}$

The WHO Global Action Plan on Antimicrobial Resistance emphasizes the importance of antibiotic resistance surveillance programs and research to strengthen the existing knowledge base and combat growing antimicrobial resistance. ${ }^{25}$ Few multicenter studies have surveyed rates of antibiotic resistance specifically in ocular pathogens, with only the Ocular Tracking Resistance in the US Today (TRUST) and Antibiotic Resistance Monitoring in Ocular micRoorganisms (ARMOR) surveillance programs publishing nationwide results in the recent past. ${ }^{26-29}$ The ARMOR study, which was initiated in 2009, is currently the only ongoing national surveillance study specifically designed to track in vitro antibacterial resistance rates among ocular pathogens. With collection of isolates over an 8-year period, the dataset is sufficiently large to allow for subanalyses to determine how factors like age impact resistance rates, as well as how resistance rates may change over time. An understanding of resistance patterns among ocular pathogens can help clinicians select appropriate treatment strategies, improve pre- and postoperative managements, and positively impact patient outcomes. Periodic updates of the ARMOR surveillance study have been published previously. ${ }^{27,28}$ Here, we report cumulative resistance profiles and trends from 2009 through 2016.

\section{Materials and methods Study design and sample collection}

The ARMOR study methodology has been described in detail previously. ${ }^{29}$ Briefly, clinically relevant isolates of S. aureus, CoNS, S. pneumoniae, H. influenzae, and P. aeruginos a cultured from ocular infections were submitted by US sites as part of the ongoing ARMOR study. Isolates of the requested species had to meet the clinical site's criteria for "significant pathogen" and be collected from ocular tissue sources (ie, eye, conjunctiva, cornea, aqueous humor, and vitreous humor). From 2009 to 2013, each participating site was invited to submit up to 65 ocular isolates per collection year, including no more than $20 \mathrm{~S}$. aureus, $20 \mathrm{CoNS}$, 5 S. pneumoniae, $5 \mathrm{H}$. influenzae, and 15 P. aeruginosa; whereas from 2014 to 2016, sites were invited to submit a maximum of 50 isolates per collection year of $S$. aureus, CoNS, S. pneumoniae, H. influenzae, and P. aeruginosa, with no more than 12 isolates of any given species. The central laboratory in ARMOR obtained pure subcultures of bacterial isolates from each of the clinical sites, although not all sites submitted samples throughout all 8 years. Enrolled sites included community hospitals, academic/university hospitals, specialty/ocular centers, and reference laboratories. Duplicate isolates from the same patient (same genus and species) were excluded from the study. Ocular pathogens collected from January 1, 2009 through December 31, 2016 were analyzed herein. As this was a laboratory study, informed consent and institutional review board approval were not required; Health Insurance Portability and Accountability Act compliance did not apply given the initial ocular samples were taken as part of routine medical care unrelated to this study, and no patient-identifying information was provided. 


\section{Susceptibility to antibiotics and testing procedures}

Bacterial isolates collected were sent to a central laboratory (Eurofins Medinet, Chantilly, VA, USA [2009-2013]; IHMA, Inc., Schaumburg, IL, USA [2014-2016]) for species confirmation and tested by the broth microdilution method in accordance with Clinical and Laboratory Standards Institute (CLSI) procedures. ${ }^{30}$ Briefly, isolates $\left(\sim 5 \times 10^{5} \mathrm{CFU} / \mathrm{mL}\right)$ were grown in 96-well microtiter panels in the presence of titrated antibiotic concentrations and incubated for 16-20 hours (staphylococci and P. aeruginosa, both in cation-adjusted Mueller-Hinton broth [CAMHB]) or 20-24 hours (S. pneumoniae in CAMHB supplemented with 3\% lysed horse blood, and H. influenzae in Haemophilus test medium) in ambient air at $35^{\circ} \mathrm{C}$. The minimum inhibitory concentration (MIC), defined as the lowest concentration of an antimicrobial agent that prevents visible growth of a microorganism, was determined for each isolate by comparing growth in control wells (no antibiotic) to growth in wells that contained varying antibiotic concentrations. ${ }^{30}$ Lower MICs are indicative of higher in vitro antibiotic potency. Susceptibility testing was conducted using frozen microtiter panels containing various antibiotics from ten classes, namely, fluoroquinolones (moxifloxacin, gatifloxacin, levofloxacin, ofloxacin, ciprofloxacin, and besifloxacin), a macrolide (azithromycin), an aminoglycoside (tobramycin), a lincosamide (clindamycin), penicillins (oxacillin/penicillin), a folate pathway inhibitor (trimethoprim), a polypeptide (polymyxin B), a phenicol (chloramphenicol), a glycopeptide (vancomycin), and a tetracycline (tetracycline); not all drugs were tested in all years of the ARMOR study. Isolates were classified as resistant (included both intermediate and full resistance) or susceptible to an antibiotic using systemic breakpoints defined by the CLSI, wherever available, to interpret MICs. ${ }^{31}$ For staphylococcal isolates, susceptibility to oxacillin was used to categorize isolates as methicillin-resistant (MR) or methicillin-susceptible (MS). Susceptibility and resistance of $S$. pneumoniae isolates to penicillin were determined using the breakpoint for oral penicillin. Isolates resistant to $\geq 3$ classes of drugs were categorized as multidrug resistant.

\section{Statistical analyses}

A one-way ANOVA was used to evaluate antibiotic resistance by patient's age categorized by decade of life. Since not all antibiotic classes were tested in each of the 8 years of the study period, the ANOVA used the means of the percentages of drug classes to which each isolate of a species or species group was resistant. Tukey's honestly significant difference
(HSD) test for pairwise differences (comparison between all possible pairs of means obtained for every patient-age decade) used the $P<0.05$ criterion for statistical significance unless otherwise indicated, and was performed when ANOVAs showed significance at the $P<0.05$ level..$^{32}$ Differences in methicillin resistance among staphylococcal isolates, specifically by decade of life, were assessed using a chisquared test. Longitudinal trends in antibiotic resistance over the study period were analyzed using the Cochran-Armitage test for linear trends in a proportion. ${ }^{33,34}$ Statistical testing was performed using Statistix 10 (Analytical Software, Tallahassee, FL, USA).

\section{Results}

\section{Source of isolates}

From January 1, 2009 through December 31, 2016, a total of 4,829 isolates (1,695 S. aureus, 1,475 CoNS, $474 S$. pneumoniae, $586 \mathrm{H}$. influenzae, and 599 P. aeruginosa) were collected from 87 sites (46 community hospitals, 29 academic/university hospitals, nine specialty/ocular centers, and three reference laboratories) across 40 states. Of these, $2,124(44.0 \%)$ and 2,261 (46.8\%) isolates were obtained from male and female patients, respectively; patient's gender was unknown for 444 (9.2\%) isolates. A total of 3,934 (81.5\%) isolates were obtained from patients with specified ages $(<10$ years: 868 [22.1\%]; 10-19 years: 173 [4.4\%]; 20-29 years: 249 [6.3\%]; 30-39 years: 256 [6.5\%]; 40-49 years: 345 [8.8\%]; 50-59 years: 457 [11.6\%]; 60-69 years: 443 [11.3\%]; 70-79 years: 450 [11.4\%]; 80-89 years: 463 [11.8\%]; and 90-99 years: 230 [5.8\%]). The precise anatomical infection source was known for 2,427 isolates (50.3\%) of which 1,198 $(49.4 \%)$ were obtained from the conjunctiva, 1,022 (42.1\%) from the cornea, 69 (2.8\%) from the aqueous humor, and $138(5.7 \%)$ from the vitreous humor.

\section{Cumulative antibiotic resistance rates}

Tables 1-3 present in vitro antibiotic resistance profiles for the cumulative dataset by species/species group, including those for $S$. aureus and CoNS by methicillin resistance phenotype.

Of the $S$. aureus collected (Table 1), $60.6 \%, 35.8 \%$, and $36.6 \%$ demonstrated in vitro resistance to azithromycin, ciprofloxacin, and methicillin (MR S. aureus [MRSA]), respectively. While some resistance to tobramycin (17.4\%) and clindamycin (15.4\%) was noted, few $S$. aureus isolates were resistant to chloramphenicol (6.1\%), trimethoprim (4.4\%), and tetracycline $(4.3 \%)$, and all were susceptible to vancomycin. Compared to MS S. aureus (MSSA) isolates, which 
Table I Cumulative resistance profiles and MICs for S. aureus isolates

\begin{tabular}{|c|c|c|c|c|c|c|c|c|c|c|c|c|}
\hline \multirow[t]{3}{*}{ Antibiotic } & \multicolumn{12}{|c|}{ S. aureus } \\
\hline & \multicolumn{4}{|l|}{ All } & \multicolumn{4}{|c|}{ MRSA } & \multicolumn{4}{|c|}{ MSSA } \\
\hline & $\mathbf{N}$ & $\% \mathbf{S}$ & $\% \mathbf{R}$ & $\mathrm{MIC}_{90}$ & $\mathbf{N}$ & $\% \mathbf{S}$ & $\% \mathbf{R}$ & $\mathrm{MIC}_{90}$ & $\mathbf{N}$ & $\% \mathbf{S}$ & $\% \mathbf{R}$ & MIC $_{90}$ \\
\hline Vancomycin & 1,695 & 100 & 0 & I & 621 & 100 & 0 & 1 & 1,074 & 100 & 0 & I \\
\hline Besifloxacin & 1,695 & $N A^{b}$ & $\mathrm{NA}^{\mathrm{b}}$ & 1 & 621 & $N A^{b}$ & $\mathrm{NA}^{\mathrm{b}}$ & 2 & $\mathrm{I}, 074$ & $N A^{b}$ & $N A^{b}$ & 0.25 \\
\hline Moxifloxacin & 1,695 & 66.4 & 33.6 & 4 & 621 & 27.2 & 72.8 & 16 & $\mathrm{I}, 074$ & 89.0 & II & I \\
\hline Gatifloxacin & 1,495 & 65.9 & 34.1 & 8 & 543 & 26.7 & 73.3 & 16 & 952 & 88.2 & 11.8 & 1 \\
\hline Ciprofloxacin & 1,695 & 64.3 & 35.8 & 128 & 621 & 24.5 & 75.5 & 256 & $\mathrm{I}, 074$ & 87.2 & 12.8 & 8 \\
\hline Levofloxacin & 1,495 & 65.7 & 34.3 & 32 & 543 & 26.2 & 73.9 & 128 & 952 & 88.2 & 11.8 & 4 \\
\hline Ofloxacin & 1,495 & 65.2 & 34.9 & $>8$ & 543 & 25.8 & 74.2 & $>8$ & 952 & 87.6 & 12.4 & 8 \\
\hline Azithromycin & 1,695 & 39.4 & 60.6 & $>512$ & 621 & 7.2 & 92.8 & $>512$ & $\mathrm{I}, 074$ & 58.0 & 42.0 & $>512$ \\
\hline Chloramphenicol & 1,495 & 93.9 & 6.1 & 8 & 543 & 89.5 & 10.5 & 16 & 952 & 96.4 & 3.6 & \begin{tabular}{|l|}
8 \\
\end{tabular} \\
\hline Clindamycin & 1,695 & 84.6 & 15.4 & $>2$ & 621 & 69.7 & 30.3 & $>2$ & $\mathrm{I}, 074$ & 93.2 & 6.8 & 0.25 \\
\hline Methicillin $^{\mathrm{a}}$ & 1,695 & 63.4 & 36.6 & $>2$ & 621 & 0 & 100 & $>4$ & $\mathrm{I}, 074$ & 100 & 0 & 0.5 \\
\hline Tetracycline & 419 & 95.7 & 4.3 & 0.5 & 103 & 90.3 & 9.7 & 4 & 316 & 97.5 & 2.5 & 0.5 \\
\hline Tobramycin & 1,695 & 82.6 & 17.4 & 128 & 621 & 58.9 & 41.1 & 256 & $\mathrm{I}, 074$ & 96.3 & 3.7 & 0.5 \\
\hline Trimethoprim & 1,495 & 95.7 & 4.4 & 4 & 543 & 94.1 & 5.9 & 2 & 952 & 96.5 & 3.5 & 4 \\
\hline
\end{tabular}

Notes: a ${ }^{O}$ xacillin was used as a surrogate for methicillin. ${ }^{b} \mathrm{Clinical}$ and Laboratory Standards Institute interpretive breakpoints are not available.

Abbreviations: $\mathrm{MIC}_{90}$, minimum inhibitory concentration that inhibits the growth of $90 \%$ of indicated isolates $(\mu \mathrm{g} / \mathrm{mL}) ; \mathrm{MRSA}$, methicillin-resistant S. aureus; MSSA, methicillin-susceptible S. aureus; NA, not applicable; \%R, percentage of resistant isolates; \%S, percentage of susceptible isolates.

Table 2 Cumulative resistance profiles and MICs for CoNS isolates

\begin{tabular}{|c|c|c|c|c|c|c|c|c|c|c|c|c|}
\hline \multirow[t]{3}{*}{ Antibiotic } & \multicolumn{12}{|c|}{ CoNS } \\
\hline & \multicolumn{4}{|l|}{ All } & \multicolumn{4}{|c|}{ MRCoNS } & \multicolumn{4}{|c|}{ MSCoNS } \\
\hline & $\mathbf{N}$ & $\% \mathbf{S}$ & \%R & $\mathrm{MIC}_{90}$ & $\mathbf{N}$ & $\% \mathbf{S}$ & $\% \mathbf{R}$ & $\mathrm{MIC}_{90}$ & $\mathbf{N}$ & $\% \mathbf{S}$ & $\% \mathbf{R}$ & $\mathrm{MIC}_{90}$ \\
\hline Vancomycin & $\mathrm{I}, 475$ & 100 & 0 & 2 & 717 & 100 & 0 & 2 & 758 & 100 & 0 & 2 \\
\hline Besifloxacin & 1,475 & $\mathrm{NA}^{\mathrm{b}}$ & $\mathrm{NA}^{\mathrm{b}}$ & 2 & 717 & $N^{b}{ }^{b}$ & $N^{b}{ }^{b}$ & 4 & 758 & $N A^{b}$ & $N A^{b}$ & 0.25 \\
\hline Moxifloxacin & $\mathrm{I}, 475$ & 68.9 & 31.1 & 16 & 717 & 48.5 & 51.5 & 32 & 758 & 88.1 & 11.9 & 1 \\
\hline Gatifloxacin & $\mathrm{I}, 33 \mathrm{I}$ & 66.9 & 33.1 & 16 & 641 & 44.2 & 55.9 & 32 & 690 & 88.1 & 11.9 & I \\
\hline Ciprofloxacin & 1,475 & 65.1 & 34.9 & 64 & 717 & 42.0 & 58.0 & 64 & 758 & 86.9 & 13.1 & 4 \\
\hline Levofloxacin & 1,331 & 66.6 & 33.4 & 128 & $64 I$ & 43.4 & 56.6 & 128 & 690 & 88.1 & 11.9 & 4 \\
\hline Ofloxacin & $\mathrm{I}, 33 \mathrm{I}$ & 66.2 & 33.8 & $>8$ & 641 & 43.1 & 56.9 & 16 & 690 & 87.7 & 12.3 & 8 \\
\hline Azithromycin & $\mathrm{I}, 475$ & 38.8 & 61.2 & $>512$ & 717 & 21.8 & \begin{tabular}{|l|}
78.2 \\
\end{tabular} & $>512$ & 758 & 54.9 & 45.1 & $>512$ \\
\hline Chloramphenicol & $\mathrm{I}, 33 \mathrm{I}$ & 98.8 & 1.2 & 8 & 641 & 98.4 & 1.6 & 8 & 690 & 99.1 & 0.9 & 4 \\
\hline Clindamycin & 1,475 & 73.9 & 26.1 & $>2$ & 717 & 63.9 & 36.1 & $>16$ & 758 & 83.4 & 16.6 & 2 \\
\hline Methicillin $^{a}$ & $\mathrm{I}, 445$ & 51.4 & 48.6 & $>2$ & 717 & 0 & 100 & $>2$ & 758 & 100 & 0 & 0.25 \\
\hline Tetracycline & 381 & 86.1 & 13.9 & $>16$ & 176 & 82.4 & 17.6 & $>16$ & 205 & 89.3 & 10.7 & 8 \\
\hline Tobramycin & $\mathrm{I}, 475$ & 83.1 & 17.0 & 8 & 717 & 72.3 & 27.8 & 32 & 758 & 93.3 & 6.7 & 4 \\
\hline Trimethoprim & $\mathrm{I}, 33 \mathrm{I}$ & 72.1 & 28.0 & $>128$ & 641 & 58.4 & 41.7 & 256 & 690 & 84.8 & 15.2 & 128 \\
\hline
\end{tabular}

Notes: ${ }^{\circ} \mathrm{Oxacillin}$ was used as a surrogate for methicillin. ${ }^{\circ} \mathrm{Clinical}$ and Laboratory Standards Institute interpretive breakpoints are not available.

Abbreviations: CoNS, coagulase-negative staphylococci; $\mathrm{MIC}_{90}$, minimum inhibitory concentration that inhibits the growth of $90 \%$ of indicated isolates $(\mu \mathrm{g} / \mathrm{mL})$; $\mathrm{MRCoNS}$, methicillin-resistant coagulase-negative staphylococci; MSCoNS, methicillin-susceptible coagulase-negative staphylococci; NA, not applicable; \%R, percentage of resistant isolates; \% , percentage of susceptible isolates.

were only notably resistant to azithromycin, higher levels of resistance to azithromycin, fluoroquinolones, tobramycin, and clindamycin were observed among MRSA isolates. Within the fluoroquinolone class, the MICs that inhibited the growth of $90 \%$ of isolates $\left(\mathrm{MIC}_{90} \mathrm{~s}\right)$ for all S. aureus, MRSA, and MSSA isolates were lower for the newer fluoroquinolones (besifloxacin, moxifloxacin, and gatifloxacin) compared to the older fluoroquinolones (ofloxacin, ciprofloxacin, and levofloxacin), with besifloxacin demonstrating the lowest $\mathrm{MIC}_{90} \mathrm{~S}$ (all S. aureus: $1 \mu \mathrm{g} / \mathrm{mL}$; MSSA: $0.25 \mu \mathrm{g} / \mathrm{mL}$; and MRSA: $2 \mu \mathrm{g} / \mathrm{mL})$. Vancomycin also demonstrated consistently low $\mathrm{MIC}_{90}$ among $S$. aureus $(1 \mu \mathrm{g} / \mathrm{mL}$ for all, MRSA, and MSSA). 
Table 3 Cumulative resistance profiles and MICs for $P$. aeruginosa, $H$. influenzae, and S. pneumoniae isolates

\begin{tabular}{|c|c|c|c|c|c|c|c|c|c|c|c|c|}
\hline \multirow[t]{2}{*}{ Antibiotic } & \multicolumn{4}{|c|}{ P. aeruginosa } & \multicolumn{4}{|c|}{ H. influenzae } & \multicolumn{4}{|c|}{ S. pneumoniae } \\
\hline & $\mathbf{N}$ & $\% \mathbf{S}$ & $\% \mathbf{R}$ & $\mathrm{MIC}_{90}$ & $\mathbf{N}$ & $\% \mathbf{S}$ & \%R & $\mathrm{MIC}_{90}$ & $\mathbf{N}$ & $\% \mathbf{S}$ & $\% \mathbf{R}$ & $\mathrm{MIC}_{90}$ \\
\hline Besifloxacin & 599 & $N A^{a}$ & $\mathrm{NA}^{\mathrm{a}}$ & 4 & 586 & $N^{a}$ & $N A^{a}$ & 0.03 & 474 & $N^{a}$ & $\mathrm{NA}^{\mathrm{a}}$ & 0.06 \\
\hline Moxifloxacin & 599 & $\mathrm{NA}^{\mathrm{a}}$ & $\mathrm{NA}^{\mathrm{a}}$ & 4 & 586 & 99.8 & 0.2 & 0.03 & 474 & 99.8 & 0.2 & 0.12 \\
\hline Gatifloxacin & 499 & 94.2 & 5.8 & 2 & 513 & 99.8 & 0.2 & 0.015 & 399 & 99.8 & 0.3 & 0.25 \\
\hline Ciprofloxacin & 599 & 94.0 & 6.0 & 0.5 & 586 & 99.8 & 0.2 & 0.015 & 474 & $N^{a}$ & $\mathrm{NA}^{\mathrm{a}}$ & 1 \\
\hline Levofloxacin & 499 & 94.8 & 5.2 & $\mathrm{I}$ & 513 & 99.8 & 0.2 & 0.03 & 399 & 100 & 0 & 1 \\
\hline Ofloxacin & 499 & 92.6 & 7.4 & 2 & 513 & 99.8 & 0.2 & 0.03 & 399 & 99.5 & 0.5 & 2 \\
\hline Azithromycin & 599 & $N A^{a}$ & $N A^{a}$ & 512 & 586 & 99.5 & 0.5 & 2 & 474 & 64.1 & 35.9 & $>128$ \\
\hline Chloramphenicol & 599 & $\mathrm{NA}^{\mathrm{a}}$ & $\mathrm{NA}^{\mathrm{a}}$ & 128 & 586 & 99.5 & 0.5 & 0.5 & 474 & 97.5 & 2.5 & 4 \\
\hline Penicillin & NT & NT & NT & NT & 586 & $\mathrm{NA}^{\mathrm{a}}$ & $N A^{a}$ & $>4$ & 474 & 66.7 & 33.3 & $I$ \\
\hline Polymyxin B & 499 & 91.4 & 8.6 & 2 & 513 & $\mathrm{NA}^{\mathrm{a}}$ & $\mathrm{NA}^{\mathrm{a}}$ & 2 & 399 & $N^{a}$ & $\mathrm{NA}^{\mathrm{a}}$ & $>128$ \\
\hline Tetracycline & 145 & $\mathrm{NA}^{\mathrm{a}}$ & $\mathrm{NA}^{\mathrm{a}}$ & 16 & 160 & 97.5 & 2.5 & 0.5 & 92 & 89.1 & 10.9 & 4 \\
\hline Tobramycin & 599 & 97.5 & 2.5 & $I$ & 586 & $\mathrm{NA}^{\mathrm{a}}$ & $\mathrm{NA}^{\mathrm{a}}$ & 2 & 474 & $N^{a}$ & $\mathrm{NA}^{\mathrm{a}}$ & 32 \\
\hline
\end{tabular}

Notes: aClinical and Laboratory Standards Institute interpretive breakpoints are not available.

Abbreviations: $\mathrm{MIC}_{90}$ minimum inhibitory concentration that inhibits the growth of $90 \%$ of indicated isolates ( $\left.\mu \mathrm{g} / \mathrm{mL}\right)$; NA, not applicable; NT, not tested; \%R, percentage of resistant isolates; \%S, percentage of susceptible isolates.

The majority of CoNS isolates collected were S. epidermidis (1,119 [75.9\%]). As shown in Table 2, cumulative in vitro resistance among CoNS isolates was greatest to azithromycin (61.2\%), methicillin (MR CoNS [MRCoNS]: $48.6 \%$ ), and ciprofloxacin (34.9\%), followed by trimethoprim (28.0\%) and clindamycin (26.1\%). Resistance to tobramycin and tetracycline was $17.0 \%$ and $13.9 \%$, respectively, while chloramphenicol resistance was low (1.2\%). Similar to MRSA isolates, higher rates of resistance were found among MRCoNS isolates when compared to MS CoNS (MSCoNS). As observed with $S$. aureus, $\mathrm{MIC}_{90}$ s were lower with newer fluoroquinolones as compared to older fluoroquinolones, and besifloxacin exhibited the lowest $\mathrm{MIC}_{90} \mathrm{~s}$ (all CoNS: 2 $\mu \mathrm{g} / \mathrm{mL}$; MSCoNS: $0.25 \mu \mathrm{g} / \mathrm{mL}$; and MRCoNS: $4 \mu \mathrm{g} / \mathrm{mL}$ ). Vancomycin $\mathrm{MIC}_{90}$ s were also consistently low among CoNS ( $2 \mu \mathrm{g} / \mathrm{mL}$ for all, MRCoNS, and MSCoNS).

Although high levels of in vitro resistance to azithromycin (35.9\%) and penicillin (33.3\%) were noted among $S$. pneumoniae isolates (Table 3), fluoroquinolone resistance was low ( $<1 \%)$. Among S. pneumoniae isolates, besifloxacin had the lowest $\mathrm{MIC}_{90}$ of all tested antibiotics $(0.06 \mu \mathrm{g} / \mathrm{mL})$.

Isolates of $P$. aeruginosa were found to be generally susceptible to all antibiotics tested (Table 3), with low in vitro resistance to polymyxin $\mathrm{B}(8.6 \%)$, tobramycin $(2.5 \%)$, and the fluoroquinolones $(5.2 \%-7.4 \%)$. $\mathrm{MIC}_{90}$ was the lowest for ciprofloxacin $(0.5 \mu \mathrm{g} / \mathrm{mL})$.

Similarly, H. influenzae isolates collected were nearly all susceptible to the antibiotics tested (Table 3 ), with only $2.5 \%$ and $<1 \%$ in vitro resistance observed for tetracycline and the fluoroquinolones, respectively. The $\mathrm{MIC}_{90}$ s for tested antibiotics were no greater than $0.03 \mu \mathrm{g} / \mathrm{mL}$ for the fluoroquinolones,
$0.5 \mu \mathrm{g} / \mathrm{mL}$ for tetracycline and chloramphenicol, and $2 \mu \mathrm{g} /$ $\mathrm{mL}$ for azithromycin.

\section{Multidrug resistance among staphylococci}

Since methicillin resistance is often an indication of concurrent resistance to other antibiotic classes, we summarized the percentage of multidrug resistance among staphylococcal isolates (Figure 1). Overall, in vitro multidrug resistance was observed in 542 (32.0\%) S. aureus isolates and 601 (40.7\%) CoNS isolates. Rates of multidrug resistance were much higher among MR staphylococci than MS isolates, with 473 (76.2\%) MRSA isolates and 527 (73.5\%) MRCoNS isolates exhibiting resistance to $\geq 3$ antibiotic classes, compared to 69 (6.4\%) MSSA isolates and 72 (9.5\%) MSCoNS isolates. Although more likely to be multidrug resistant, all MRSA and MRCoNS isolates were susceptible to vancomycin.

\section{Antibiotic resistance rates by patient's age}

Patient's age was known for $550(14.0 \%)$ MRSA, 865 (22.0\%) MSSA, 564 (14.3\%) MRCoNS, 612 (15.6\%) MSCoNS, $509(12.9 \%)$ P. aeruginosa, $460(11.7 \%)$ H. influenzae, and 374 (9.5\%) S. pneumoniae isolates. Analysis of the mean percentage of in vitro resistance by patient's age categorized by decade of life showed differences among $S$. aureus $(P<0.0001)$, CoNS $(P<0.0001), P$. aeruginosa $(P=0.0469)$, and $S$. pneumoniae $(P=0.0172)$. For $S$. aureus, pairwise differences were evident between patients aged $\geq 80$ years $(\geq 35.2 \%$ resistance) and those aged $<80$ years (resistance between $14.3 \%$ and $26.9 \%$ ). Among CoNS, pairwise differences in resistance were identified in patients aged $\geq 70$ years $(\geq 31.3 \%)$ 


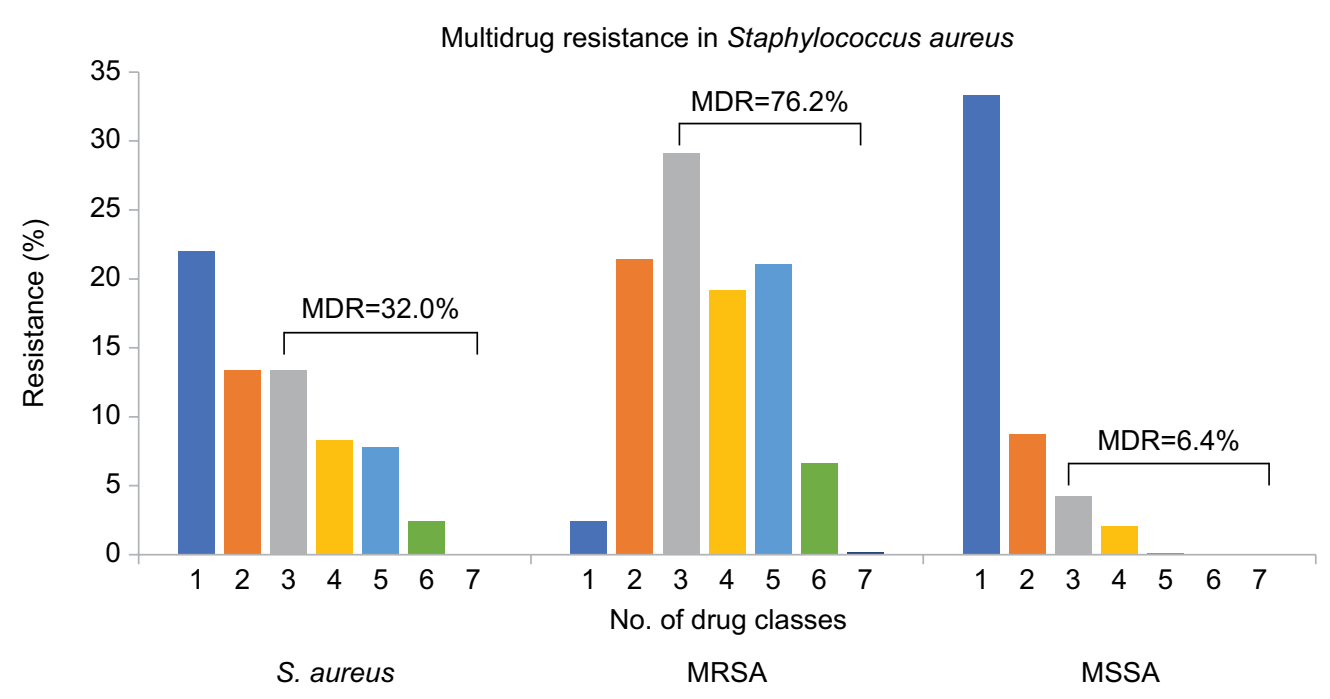

Multidrug resistance in coagulase-negative staphylococci

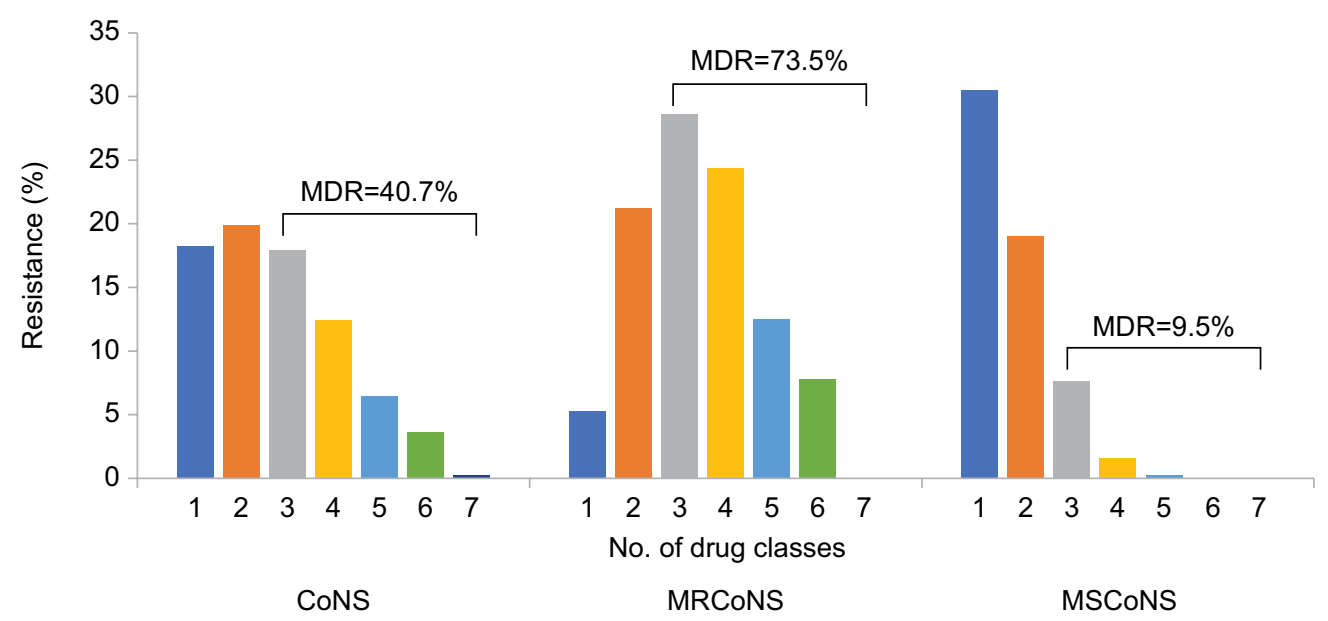

Figure I Multidrug resistance in staphylococci.

Notes: Isolates were tested against azithromycin, chloramphenicol, ciprofloxacin, clindamycin, oxacillin (methicillin), tetracycline, tobramycin, trimethoprim, and vancomycin. Abbreviations: CoNS, coagulase-negative staphylococci; MDR, multidrug resistance; MRCoNS, methicillin-resistant coagulase-negative staphylococci; MRSA, methicillinresistant S. aureus; MSCoNS, methicillin-susceptible coagulase-negative staphylococci; MSSA, methicillin-susceptible S. aureus.

vs those aged $10-19,20-29$, and $50-59$ years $(18.6 \%, 19.6 \%$, and $23.0 \%$, respectively), as well as in patients aged $80-89$ years (32.5\%) vs 30-39 years (22.8\%). When Tukey's HSD test used the $P<0.1$ criterion for statistical significance, pairwise differences were observed between patients aged $20-29$ years $(2.2 \%$ resistance) and those aged $50-59$ years (10.4\% resistance) among P. aeruginosa isolates; however, no pairwise differences were identified for $S$. pneumoniae.

Consistent with the mean percentage of resistance findings, significant differences were found in in vitro methicillin resistance specifically for $S$. aureus and CoNS based on patient's age by decade of life $(P<0.0001$ for both; Figure 2$)$. In general, methicillin resistance appeared higher in older age groups.

\section{Longitudinal trends in antibiotic resistance}

Figure 3 presents in vitro rates of methicillin resistance among staphylococci over the 8 years of the ARMOR study. Methicillin resistance in $S$. aureus ranged from $23.4 \%$ to $50.0 \%$, whereas methicillin resistance in CoNS ranged from $42.9 \%$ to $57.0 \%$. While a small but significant decrease in resistance to methicillin was reported among $S$. aureus isolates $(P<0.0001)$, methicillin resistance did not decrease for CoNS over the 8-year time frame.

Figure 4 presents trends in in vitro antibiotic resistance over the 8 years of the ARMOR study for other antibiotics among S. aureus, MRSA, CoNS, MRCoNS, S. pneumoniae, 


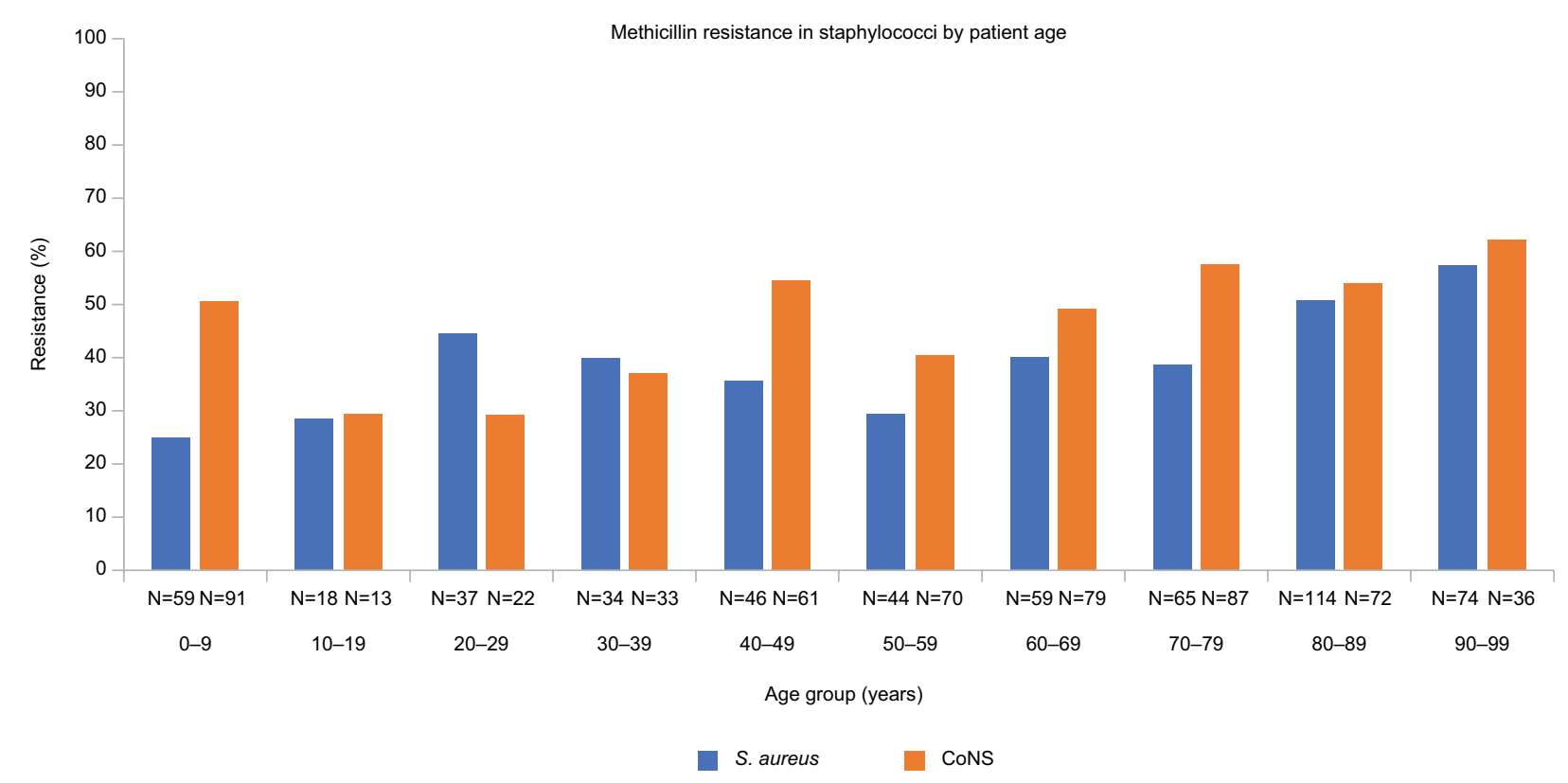

Figure 2 Methicillin resistance in staphylococci by patient age.

Notes: Methicillin resistance among staphylococci was evaluated by patient decade of life. Significant differences in mean percent methicillin resistance were found, with higher rates of resistance observed in older patients $(P<0.0001$ for both $S$. aureus and CoNS).

Abbreviation: CoNS, coagulase-negative staphylococci.

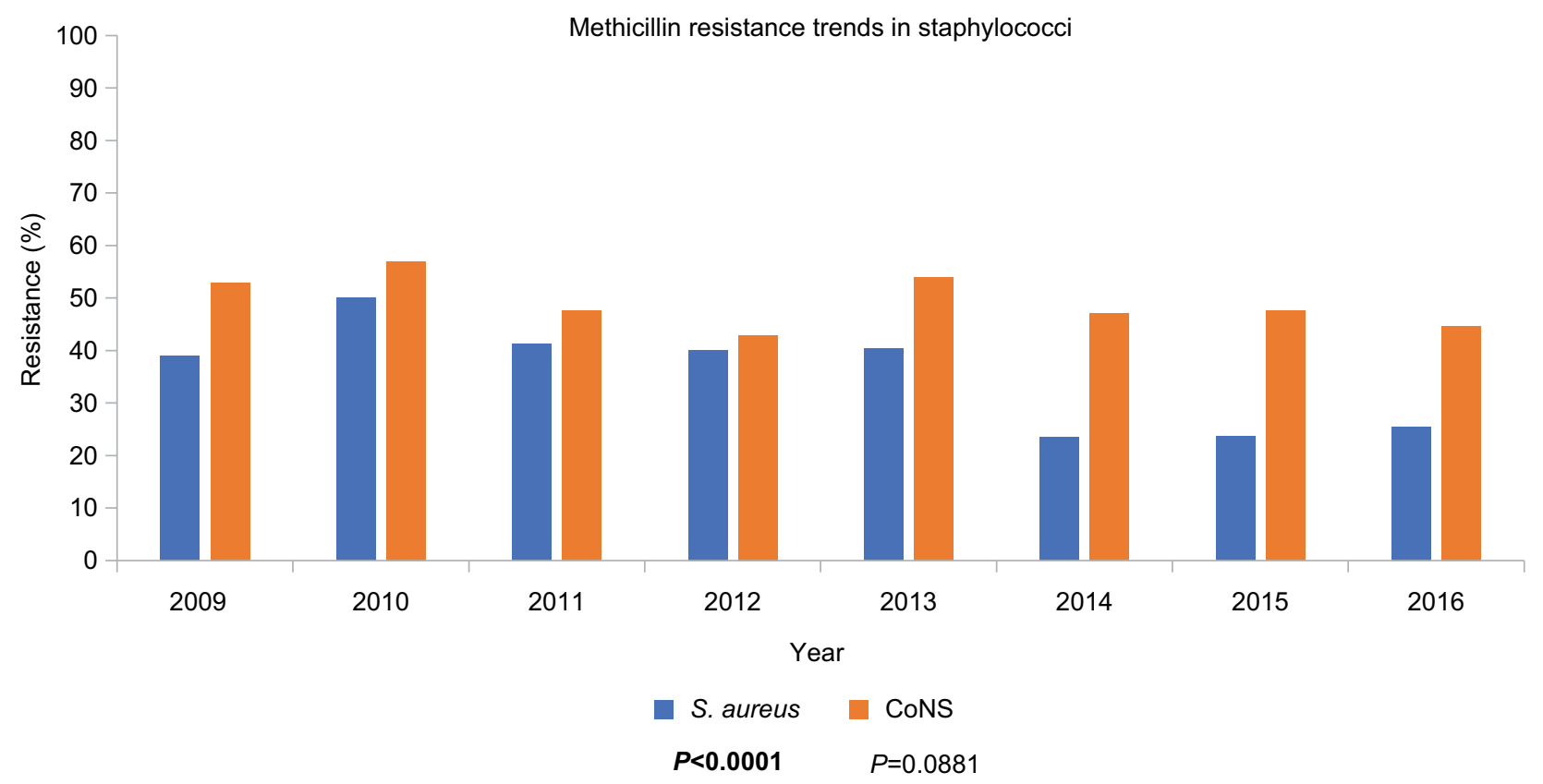

Figure 3 Trends in methicillin resistance over time (ARMOR, 2009-2016) in staphylococci.

Notes: Methicillin resistance rates among staphylococci over the course of the ARMOR study are shown. A decrease in methicillin resistance over time was observed among S. aureus isolates $(P<0.000$ I, bold font) but not among CoNS isolates.

Abbreviations: ARMOR, Antibiotic Resistance Monitoring in Ocular micRoorganisms; CoNS, coagulase-negative staphylococci.

and $P$. aeruginosa. Longitudinal trends varied among staphylococci. Resistance to azithromycin $(P<0.0001)$, chloramphenicol $(P=0.0042)$, ciprofloxacin $(P<0.0001)$, and tobramycin $(P<0.0001)$ decreased significantly among $S$. aureus isolates. Among CoNS isolates, a decrease in resistance to ciprofloxacin $(P=0.0009)$ and a significant increase 


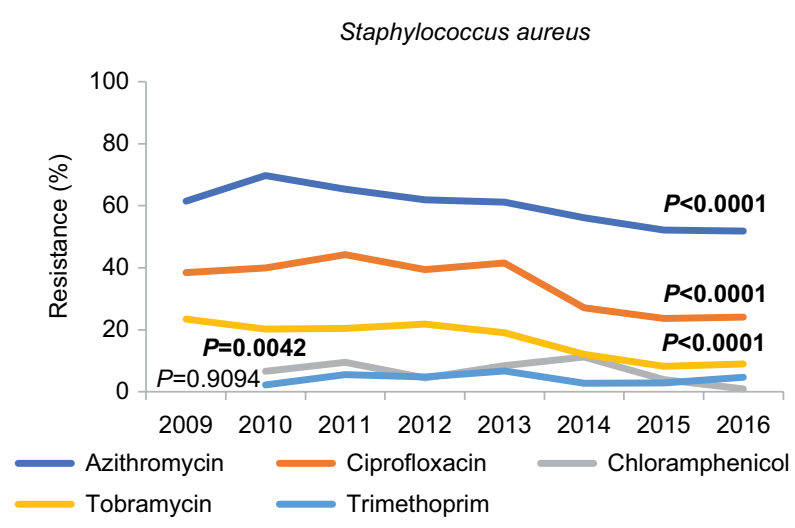

CoNS

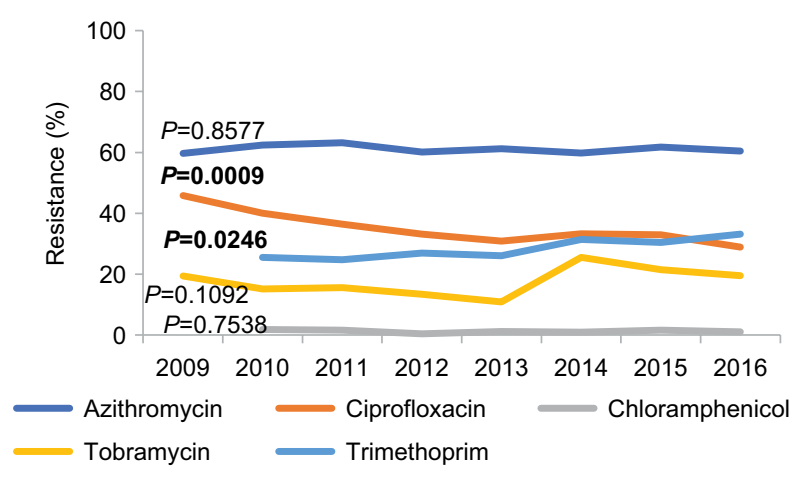

Streptococcus pneumoniae

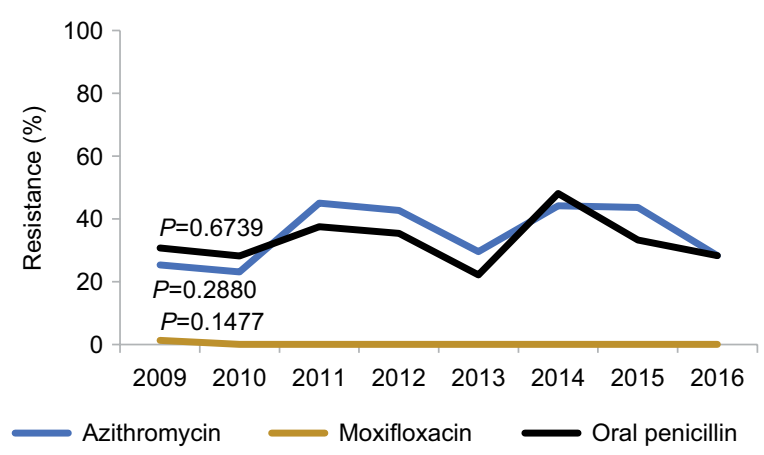

MRSA

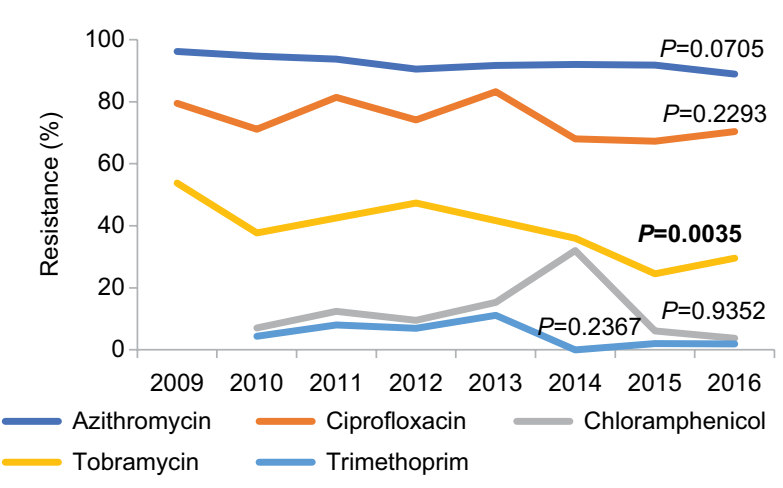

MRCoNS

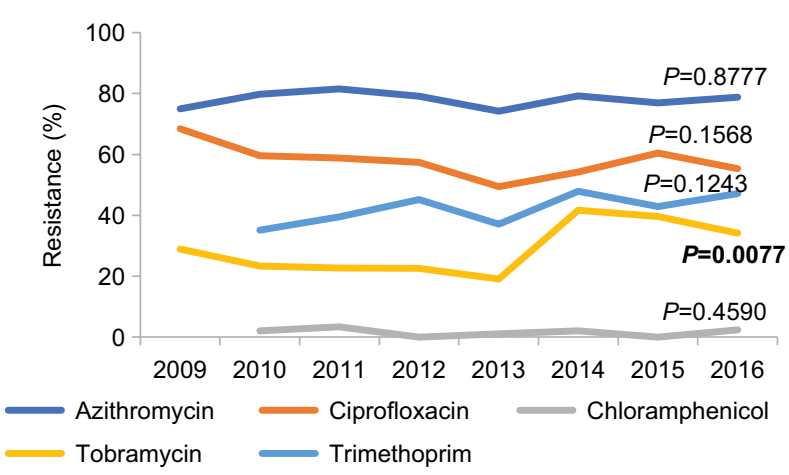

Pseudomonas aeruginosa

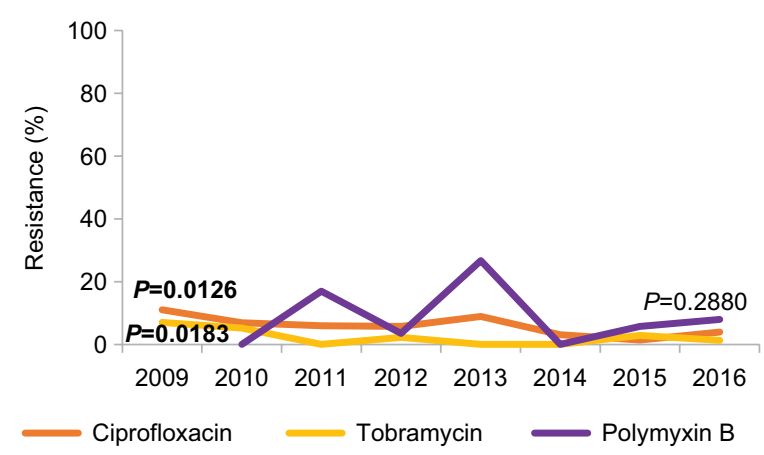

Figure 4 Trends in antibiotic resistance over time (ARMOR, 2009-2016).

Notes: Trends in antibiotic resistance over 8 years of ARMOR are shown for representative antibiotics for which systemic breakpoints were available. Significant changes $(P<0.05$, bold font) in antibiotic resistance trends over time were observed.

Abbreviations: ARMOR, Antibiotic Resistance Monitoring in Ocular micRoorganisms; CoNS, coagulase-negative staphylococci; MRCoNS, methicillin-resistant coagulasenegative staphylococci; MRSA, methicillin-resistant S. aureus.

in resistance to trimethoprim $(P=0.0246)$ were observed. Among MR staphylococcal isolates, significant differences in the rates of tobramycin resistance were observed over time; increasing resistance was observed among MRCoNS isolates $(P=0.0077)$, while decreasing resistance was observed among MRSA isolates $(P=0.0035)$.

Among $P$. aeruginosa isolates, significant decreases in ciprofloxacin $(P=0.0126)$ and tobramycin $(P=0.0183)$ resistance were observed over the course of the study. Resistance among S. pneumoniae isolates remained consistent, with no discernable changes over time.

\section{Discussion}

The ARMOR surveillance study examines in vitro antibiotic susceptibility/resistance profiles among common ocular pathogens collected prospectively from sites across the United States. ${ }^{29}$ While several single-center studies have reported in vitro antibiotic resistance rates among ocular 
isolates, ARMOR is the only ongoing study to do so on a nationwide scale. With almost 5,000 isolates included, the present report evaluates cumulative resistance rates and trends in resistance over 8 years of the ARMOR study, expanding on previously published 5-year and 7-year analyses. ${ }^{27,28}$ Current ARMOR results demonstrate substantial levels of in vitro resistance to commonly used antibiotics, particularly among staphylococcal isolates, of which nearly half were MR. Multidrug resistance analyses showed approximately two in every five staphylococcal isolates and approximately three in every four MRSA or MRCoNS isolates exhibited in vitro resistance to three or more antibiotic classes. Higher levels of overall mean in vitro resistance were found among isolates from elderly patients, especially when considering methicillin resistance among staphylococci. Isolates of $S$. pneumoniae showed high levels of in vitro resistance $(-35 \%)$ to azithromycin and to oral penicillin, but were susceptible to fluoroquinolones and other tested drugs. Conversely, resistance among $P$. aeruginosa and $H$. influenzae remained low $(<9 \%)$ against almost all antibiotics tested. Significant declines in in vitro resistance were observed for many antibiotic-pathogen combinations, including a decrease in methicillin resistance among $S$. aureus, although an increase in trimethoprim resistance was seen among CoNS isolates.

Results from the current analysis are generally consistent with recent reports on the prevalence of in vitro methicillin resistance among staphylococci from ocular infections in the United States, with some variations. Miller ${ }^{35}$ reported similar levels of methicillin resistance among 967 S. aureus and 287 S. epidermidis isolates from ocular infections collected at the Bascom Palmer Eye Institute between 2011 and 2015 (42.1\% and $46.3 \%$, respectively), in line with the current study. However, in an analysis of ocular pathogen data collected at Mount Sinai Hospital (2010-2015), which included 113 S. aureus isolates, a lower rate of MRSA $(\sim 25 \%)$ was observed; although a trend towards decreasing MRSA prevalence over the 6 -year study period was noted (31.3\% in 2010 to $14.1 \%$ in 2015), the change was not statistically significant. ${ }^{36}$ It is unclear whether the differences observed between studies reflect regional variations among predominant infective strains or are representative of a temporal decline in MRSA prevalence among ocular infections. Nonetheless, patterns of resistance among staphylococci to fluoroquinolones, macrolides, and other antibiotic agents (when tested) were similar to the current ARMOR analysis in these studies, with MR isolates exhibiting increased resistance compared to MS isolates. ${ }^{35,36}$
As previously reported, ${ }^{27-29}$ large differences in $\mathrm{MIC}_{90} \mathrm{~S}$ for staphylococci were evident within the fluoroquinolone class of drugs, with older fluoroquinolones having higher $\mathrm{MIC}_{90} \mathrm{~s}$ compared to newer ones. Besifloxacin had the lowest $\mathrm{MIC}_{90} \mathrm{~s}$ among staphylococci regardless of methicillin phenotype, attesting to its potent in vitro activity. Due to the lack of a systemic besifloxacin formulation, interpretive criteria are not available to categorize bacterial isolates as susceptible or resistant to besifloxacin. In the absence of such breakpoints, evaluation of besifloxacin MIC data alongside that of comparator agents allows for an assessment of its in vitro potency; however, the clinical relevance of these findings is unknown. Previous studies have shown besifloxacin to provide balanced, potent inhibition of both bacterial DNA gyrase and topoisomerase, with minimum bactericidal concentrations generally within one dilution of the MIC. ${ }^{37}$ The lack of any meaningful changes in besifloxacin $\mathrm{MIC}_{90} \mathrm{~s}$ for all study species over the 8-year period suggests its activity has remained stable over time and may be a reflection of that balanced inhibition. Of note, all staphylococcal isolates were susceptible in vitro to vancomycin, which had similar $\mathrm{MIC}_{90}$ s to those for besifloxacin. The absence of vancomycin resistance and correspondingly low vancomycin $\mathrm{MIC}_{90} \mathrm{~S}$ is particularly reassuring given that vancomycin is commonly compounded for ophthalmic use in the treatment of resistant ocular infections.

In terms of microbial resistance by patient age, the rates of overall mean resistance, and specifically methicillin resistance, were higher in older patients, consistent with previous ARMOR data analyses and other studies. ${ }^{28,29,36,38-40}$ This association may be because older patients often spend more time in hospitals and health care centers, and are, therefore, more likely than younger patients to be exposed to antibiotic-resistant bacteria common in these environments. Relationships between antibiotic resistance rates and patient age have also been reported in studies of systemic infections. ${ }^{41-43} \mathrm{~A}$ recent retrospective survey of data from 511 MRSA cases collected between 2008 and 2009 found that greater rates of resistance were observed among older patients for fluoroquinolones but not with other antibiotic classes. ${ }^{41}$

Analysis of resistance rates over time showed decreasing trends for in vitro resistance, which is promising and generally consistent with earlier ARMOR study reports, with few exceptions. ${ }^{27,28}$ The current analysis found decreases in resistance to ciprofloxacin (among $S$. aureus, CoNS, MRCoNS, and . aeruginosa) and tobramycin (among S. aureus, MRSA, and $P$. aeruginosa), as well as to azithromycin and chloramphenicol (among $S$. aureus). Of particular note, a decrease 
in methicillin resistance was observed among isolates of $S$. aureus, but not CoNS, in the present study; this decline was not evident early in the ARMOR study, ${ }^{28}$ but was detected in the 7-year trend analysis ${ }^{27}$ and has continued over the current 8 -year time frame. Additionally, the significant increase in trimethoprim resistance among CoNS seen in this study was not reported previously.

In vitro resistance rates and susceptibility profiles in the present study are similar to reported data for bacterial isolates with specific ocular diagnoses, such as conjunctivitis, ${ }^{44}$ keratitis, ${ }^{12,45}$ and endophthalmitis. ${ }^{13,15,17}$ In a 20 -year review of antibiotic resistance among 398 S. aureus keratitis isolates (1993-2012), all were susceptible to vancomycin, and fluoroquinolone resistance was prevalent, with MRSA representing $30.7 \%$ of the total. ${ }^{12}$ A study assessing rates of antibiotic sensitivity among 998 isolates collected over 25 years (1987-2011) from endophthalmitis cases also identified substantial resistance to fluoroquinolones in gram-positive isolates and a decreasing trend in resistance to aminoglycosides, including tobramycin. However, findings from that study indicated an increase in methicillin resistance over time (from $18 \%$ and $31 \%$ among $S$. aureus and S. epidermidis, respectively, to $>50 \%$ each), in contrast to the present ARMOR analysis. ${ }^{13}$

In addition, current ARMOR results are generally consistent with antibiotic resistance rates observed in surveillance studies for non-ocular infections requiring systemic antibiotic treatment. ${ }^{46-48}$ The Linezolid Experience and Accurate Determination of Resistance (LEADER) program recently reported high methicillin resistance rates among 3,031 (46\%) S. aureus and 924 (59\%) CoNS isolates collected primarily from bloodstream, respiratory tract, and skin and soft tissue infections in the United States between 2011 and 2015, with $\sim 60 \%$ and upwards of $70 \%$ of MR staphylococci exhibiting resistance to fluoroquinolones and macrolides, respectively. ${ }^{47}$ Likewise, the latest United States report of 21,056 clinical S. aureus isolates tested in the Assessing Worldwide Antimicrobial Resistance Evaluation (AWARE) study from 2010 to 2016 found methicillin resistance rates decreased from $50.0 \%$ to $42.2 \% ;>65 \%$ of MRSA isolates showed resistance to fluoroquinolones and macrolides over the 7 -year period. ${ }^{49}$ Staphylococcal resistance rates for clindamycin and tetracycline in the LEADER and AWARE studies were similar to those observed in the current study. ${ }^{47,48}$ Resistances among $S$. pneumoniae isolates in these studies were also largely consistent with those in the ARMOR study; oral penicillin and macrolide resistance rates were, respectively, $36.8 \%$ and $42.9 \%$ in LEADER $(n=850)^{47}$ and $41.3 \%$ and $44.6 \%$ in
AWARE ( $n=8,768),{ }^{46}$ compared to $33.3 \%$ and $35.9 \%$ in the present analysis. Further comparisons of data from systemic infections with ARMOR results were hindered by differences in the antibiotic agents tested between studies.

Resistance trends based on source of isolate by geography for this 8-year dataset were recently published elsewhere and showed differences in antibiotic resistance rates based on geographic region. ${ }^{49}$ Significant trends were noted for $S$. aureus (high in the South [28.1\%]; low in the West [16.8\%]), S. pneumoniae (high in the Midwest [14.5\%]; low in the West [7.6\%]), and P. aeruginosa (high in the Midwest [8.5\%]; low in the West [2.9\%]), with no regional differences found among CoNS and H. influenzae isolates. While the underlying reasons for observed geographic disparities have yet to be elucidated, it is possible that climate variations and/or differences in prescribing patterns and antibiotic stewardship programs may impact regional antibiotic resistance rates.

The current analysis of ARMOR has several limitations. The study evaluated in vitro resistance rates in ocular pathogens based on systemic breakpoints, which were established based on pharmacokinetic and pharmacodynamic data obtained following systemic administration of antibiotics. Currently, associations between systemic breakpoints and topical antibiotic concentrations used in ocular infections have not been determined. It is assumed that concentrations achieved at the site of infection after topical ophthalmic use are at least as high as, if not higher than, those achieved after systemic administration. ${ }^{50}$ However, blinking and tear turnover, along with barriers to ocular penetration, work to decrease antibiotic concentrations following topical ophthalmic use. Another limitation is the potential for sampling bias due to the infrequent practice of culturing bacterial pathogens. With the exception of intraocular infections, ocular cultures are seldom collected during routine clinical practice, and infections are generally treated empirically. As a result, cultures, when collected, may be representative of more severe infections that do not respond to initial empirical treatment.

\section{Conclusion}

Results from this analysis of 8-year ARMOR data demonstrate small trends in antibiotic resistance, with encouraging decreases noted in rates of resistance to certain antibiotics. However, rates of antibiotic resistance among gram-positive organisms remain high, especially for methicillin resistance and multidrug resistance among staphylococci. These findings are consistent with published studies in the scientific literature for both ocular and non-ocular staphylococcal infections. These data can assist health care practitioners in 
making informed choices regarding the treatment of ocular infections with ophthalmic antibiotics.

\section{Data availability}

The presented data are from the ARMOR study and are available from the corresponding author upon request as appropriate.

\section{Acknowledgments}

Editorial assistance was provided by Christine M. Sanfilippo, $\mathrm{PhD}$, an employee of Bausch \& Lomb Incorporated.

The ARMOR study is funded by Bausch \& Lomb Incorporated, which was responsible for the design and conduct of the study, as well as data collection, management, and analysis. Medical writing support was provided by Cactus Communications, Inc., and was funded by Bausch \& Lomb Incorporated.

\section{Author contributions}

All authors contributed to data analysis, drafting and revising the article, gave final approval of the version to be published, and agree to be accountable for all aspects of the work.

\section{Disclosure}

RKT has received advisory board/consultancy fees from Bausch \& Lomb Incorporated. PAA has received grants, advisory board/consultancy fees, and non-financial support from Bausch \& Lomb Incorporated. The authors report no other conflicts of interest in this work.

\section{References}

1. Smith RA, M'Ikanatha NM, Read AF. Antibiotic resistance: a primer and call to action. Health Commun. 2015;30(3):309-314.

2. Ventola CL. The antibiotic resistance crisis: part 1: causes and threats. P T. 2015;40(4):277-283.

3. Dave SB, Toma HS, Kim SJ. Changes in ocular flora in eyes exposed to ophthalmic antibiotics. Ophthalmology. 2013;120(5):937-941.

4. Grzybowski A, Brona P, Kim SJ. Microbial flora and resistance in ophthalmology: a review. Graefes Arch Clin Exp Ophthalmol. 2017;255(5):851-862.

5. Azari AA, Barney NP. Conjunctivitis: a systematic review of diagnosis and treatment. JAMA. 2013;310(16):1721-1729.

6. Bertino JS Jr. Impact of antibiotic resistance in the management of ocular infections: the role of current and future antibiotics. Clin Ophthalmol. 2009;3:507-521.

7. Sharma S. Antibiotic resistance in ocular bacterial pathogens. Indian $J$ Med Microbiol. 2011;29(3):218-222.

8. AAO PPP Cataract/Anterior Segment Panel, Hoskins Center for Quality Eye Care. Cataract in the Adult Eye Preferred Practice Pattern. San Francisco, CA: American Academy of Ophthalmology; 2016.

9. AAO PPP Refractive Management/Intervention Panel, Hoskins Center for Quality Eye Care. Refractive Errors \& Refractive Surgery Preferred Practice Pattern. San Francisco, CA: American Academy of Ophthalmology; 2017.
10. Teweldemedhin M, Gebreyesus H, Atsbaha AH, Asgedom SW, Saravanan M. Bacterial profile of ocular infections: a systematic review. $B M C$ Ophthalmol. 2017;17(1):212.

11. Kowalski RP. Is antibiotic resistance a problem in the treatment of ophthalmic infections? Expert Rev Ophthalmol. 2013;8(2):119-126.

12. Chang VS, Dhaliwal DK, Raju L, Kowalski RP. Antibiotic resistance in the treatment of Staphylococcus aureus keratitis: a 20-year review. Cornea. 2015;34(6):698-703.

13. Gentile RC, Shukla S, Shah M, et al. Microbiological spectrum and antibiotic sensitivity in endophthalmitis: a 25-year review. Ophthalmology. 2014;121(8):1634-1642.

14. Schimel AM, Miller D, Flynn HW Jr. Endophthalmitis isolates and antibiotic susceptibilities: a 10-year review of culture-proven cases. Am J Ophthalmol. 2013;156(1):e51:50-52.

15. Slean GR, Shorstein NH, Liu L, Paschal JF, Winthrop KL, Herrinton LJ. Pathogens and antibiotic sensitivities in endophthalmitis. Clin Exp Ophthalmol. 2017;45(5):481-488.

16. Kessel L, Flesner P, Andresen J, Erngaard D, Tendal B, Hjortdal J. Antibiotic prevention of postcataract endophthalmitis: a systematic review and meta-analysis. Acta Ophthalmol. 2015;93(4):303-317.

17. Holland EJ, Mcdonald MB, Parekh JG, Sheppard JD. Antibiotic resistance in acute postoperative endophthalmitis. Ophthalmology. 2014;121(11 Suppl):S1-S9; quiz S10-12.

18. Comstock TL, Paterno MR, Usner DW, Pichichero ME. Efficacy and safety of besifloxacin ophthalmic suspension $0.6 \%$ in children and adolescents with bacterial conjunctivitis: a post hoc, subgroup analysis of three randomized, double-masked, parallel-group, multicenter clinical trials. Paediatr Drugs. 2010;12(2):105-112.

19. Morris TW, Gearinger LS, Usner DW, et al. Integrated analysis of three bacterial conjunctivitis trials of besifloxacin ophthalmic suspension, 0.6\%: microbiological eradication outcomes. Clin Ophthalmol. 2011;5:1359-1367.

20. Chen FV, Chang TC, Cavuoto KM. Patient demographic and microbiology trends in bacterial conjunctivitis in children. J AAPOS. 2018;22(1):66-67.

21. Stapleton F, Carnt N. Contact lens-related microbial keratitis: how have epidemiology and genetics helped us with pathogenesis and prophylaxis. Eye (Lond). 2012;26(2):185-193.

22. Brown L. Resistance to ocular antibiotics: an overview. Clin Exp Optom. 2007;90(4):258-262.

23. Mah FS, Sanfilippo CM. Besifloxacin: efficacy and safety in treatment and prevention of ocular bacterial infections. Ophthalmol Ther. 2016;5(1):1-20.

24. Deschenes J, Blondeau J. Besifloxacin in the management of bacterial infections of the ocular surface. Can J Ophthalmol. 2015;50(3): 184-191.

25. Global Action Plan on Antimicrobial Resistance. World Health Organization; 2015. Available from: http://www.wpro.who.int/entity/ drug_resistance/resources/global_action_plan_eng.pdf. Accessed October 10, 2018.

26. Asbell PA, Colby KA, Deng S, et al. Ocular TRUST: nationwide antimicrobial susceptibility patterns in ocular isolates. Am J Ophthalmol. 2008;145(6):951-958.

27. Asbell PA, Sanfilippo CM. Antibiotic resistance trends among ocular pathogens in the US - cumulative results from the antibiotic resistance monitoring in ocular microorganisms (armor) surveillance study. US Ophthalmic Review. 2017;10(1):35-38.

28. Asbell PA, Sanfilippo CM, Pillar CM, DeCory HH, Sahm DF, Morris TW. Antibiotic resistance among ocular pathogens in the United States: five-year results from the Antibiotic Resistance Monitoring in Ocular Microorganisms (ARMOR) surveillance study. JAMA Ophthalmol. 2015;133(12):1445-1454.

29. Haas W, Pillar CM, Torres M, Morris TW, Sahm DF. Monitoring antibiotic resistance in ocular microorganisms: results from the Antibiotic Resistance Monitoring in Ocular micRorganisms (ARMOR) 2009 surveillance study. Am J Ophthalmol. 2011;152(4):e563:567-574. 
30. Clinical and Laboratory Standards Institute. M07-Ed10. Methods for Dilution Antimicrobial Susceptibility Tests for Bacteria that Grow Aerobically; Approved Standard-Tenth Edition. 10th ed. Wayne, PA: Clinical and Laboratory Standards Institute; 2015.

31. Clinical and Laboratory Standards Institute. M100-Ed26. Performance Standards for Antimicrobial Susceptibility Testing. 26th ed. Wayne, PA: Clinical and Laboratory Standards Institute; 2016.

32. Mchugh ML. Multiple comparison analysis testing in ANOVA. Biochem Med (Zagreb). 2011;21(3):203-209.

33. Armitage P. Tests for linear trends in proportions and frequencies. Biometrics. 1955;11(3):375-386.

34. Cochran WG. Some methods for strengthening the common $\chi^{2}$ tests. Biometrics. 1954;10(4):417-451.

35. Miller D. Update on the epidemiology and antibiotic resistance of ocular infections. Middle East Afr J Ophthalmol. 2017;24(1):30-42.

36. Oydanich M, Dingle TC, Hamula CL, Ghisa C, Asbell P. Retrospective report of antimicrobial susceptibility observed in bacterial pathogens isolated from ocular samples at Mount Sinai Hospital, 2010 to 2015. Antimicrob Resist Infect Control. 2017;6(1):29.

37. Besivance ${ }^{\circledR}$ (besifloxacin ophthalmic suspension) $0.6 \%$ [prescribing information]. Bridgewater, NJ: Bausch \& Lomb Incorporated; June 2016.

38. Chiquet C, Maurin M, Altayrac J, et al. Correlation between clinical data and antibiotic resistance in coagulase-negative Staphylococcus species isolated from 68 patients with acute post-cataract endophthalmitis. Clin Microbiol Infect. 2015;21(6):592.e1-592.e8.

39. Fintelmann RE, Hoskins EN, Lietman TM, et al. Topical fluoroquinolone use as a risk factor for in vitro fluoroquinolone resistance in ocular cultures. Arch Ophthalmol. 2011;129(4):399-402.

40. Olson R, Donnenfeld E, Bucci FA, et al. Methicillin resistance of Staphylococcus species among health care and nonhealth care workers undergoing cataract surgery. Clin Ophthalmol. 2010;4:1505-1514.

41. Garcia A, Delorme T, Nasr P. Patient age as a factor of antibiotic resistance in methicillin-resistant Staphylococcus aureus. J Med Microbiol. 2017;66(12):1782-1789.
42. Arkwright PD, Daniel TO, Sanyal D, David TJ, Patel L. Age-related prevalence and antibiotic resistance of pathogenic staphylococci and streptococci in children with infected atopic dermatitis at a singlespecialty center. Arch Dermatol. 2002;138(7):939-941.

43. Delorme T, Rose S, Senita J, Callahan C, Nasr P. Epidemiology and susceptibilities of methicillin-resistant Staphylococcus aureus in Northeastern Ohio. Am J Clin Pathol. 2009;132(5):668-677.

44. Adebayo A, Parikh JG, Mccormick SA, et al. Shifting trends in in vitro antibiotic susceptibilities for common bacterial conjunctival isolates in the last decade at the New York Eye and Ear Infirmary. Graefes Arch Clin Exp Ophthalmol. 2011;249(1):111-119.

45. Ni N, Nam EM, Hammersmith KM, et al. Seasonal, geographic, and antimicrobial resistance patterns in microbial keratitis: 4-year experience in eastern Pennsylvania. Cornea. 2015;34(3):296-302.

46. Pfaller MA, Mendes RE, Duncan LR, Flamm RK, Sader HS. In Vitro activities of ceftaroline and comparators against Streptococcus pneumoniae isolates from U.S. Hospitals: results from seven years of the AWARE surveillance program (2010 to 2016). Antimicrob Agents Chemother. 2018;62(2):e01555-17.

47. Pfaller MA, Mendes RE, Streit JM, Hogan PA, Flamm RK. Five-year summary of in vitro activity and resistance mechanisms of linezolid against clinically important gram-positive cocci in the United States from the LEADER surveillance program (2011 to 2015). Antimicrob Agents Chemother. 2017;61(7):e00609-17.

48. Sader HS, Mendes RE, Streit JM, Flamm RK. Antimicrobial susceptibility trends among Staphylococcus aureus isolates from U.S. hospitals: results from 7 years of the Ceftaroline (aware) surveillance Program, 2010 to 2016. Antimicrob Agents Chemother. 2017;61(9): e01043-17.

49. Asbell PA, Pandit RT, Sanfilippo CM. Antibiotic resistance rates by geographic region among ocular pathogens collected during the ARMOR surveillance study. Ophthalmol Ther. Epub 2018 Aug 9.

50. Kowalski RP, Yates KA, Romanowski EG, Karenchak LM, Mah FS, Gordon YJ. An ophthalmologist's guide to understanding antibiotic susceptibility and minimum inhibitory concentration data. Ophthalmology. 2005;112(11):1987.
Clinical Optometry

\section{Publish your work in this journal}

Clinical Optometry is an international, peer-reviewed, open access journal publishing original research, basic science, clinical and epidemiological studies, reviews and evaluations on clinical optometry. All aspects of patient care are addressed within the journal as well as the practice of optometry including economic and business analyses. Basic and clinical Submit your manuscript here: https://www.dovepress.com/clinical-optometry-journal

\section{Dovepress}

research papers are published that cover all aspects of optics, refraction and its application to the theory and practice of optometry. The manuscript management system is completely online and includes a very quick and fair peer-review system, which is all easy to use. Visit http://www.dovepress. com/testimonials.php to read real quotes from published authors. 